\title{
Do Small Firms Pay to Stay? An Experimental Investigation
}

\author{
Ammara Mahmood, \\ Wilfrid Laurier University, Waterloo \\ Nir Vulkan, \\ Said Business School, Oxford
}

We analyze the impact of market share on pricing strategies in markets with customer recognition. We show that in horizontally differentiated competitive markets prices vary with market share. . In asymmetric markets having a weak brand is a sufficient condition for discounts to existing customers, resulting in the less preferred firms offering discounts for loyalty, and dominant brands offering discounts for switching. More specifically, a low inherited market share provides sufficient condition for discounts to existing customers. In contrast, when market share is sufficiently high firms offer discounts for switching. A customer retention strategy enables smaller firms to increase profits and market share while the large firm loses market share. We further contribute to the literature on BBPD by conducting controlled experiments. In line with our predictions we find that the price setting behavior of experimental participants varies with market share and that having a smaller inherited customer base results in loyalty rewards. 


\section{Introduction}

Advances in data collection and customer recognition in digital and physical shopping environments have made dynamic pricing both viable and desirable across different industries (Deksnyter and Lydeka, 2012). The analysis of large amounts of consumer data enables retailers to adjust their prices continuously and potentially to provide customized offers at the individual level. For instance, recently at a Safeway supermarket in Denver USA, a pack of bottled water was priced at $\$ 2.71$ for customer A, while customer B was charged $\$ 3.69$ for the same pack. Customer A had not purchased the bottled water in the past and was charged a lower price, while customer B who had purchased the water during previous shopping trips was charged a higher price (Clifford, 2012). Similarly, the online retail giant Amazon collects data on approximately 200 million customer accounts which equals to 1 billion GB of information stored in over 1.4 million servers (Big Data Zone, 2016). This enables Amazon to review each consumer's activity regularly on the website, what products she is looking for, her purchase history, preferences and the prices of primary competitors for the desired product or category. While behavior-based price discrimination (BBPD) is widely prevalent, the outcome of BBPD varies across competitive markets. For instance, it is common practice amongst some subscription providers like cell phone companies to give the best deals to their existing customers, while others like insurance providers may charge higher premiums to existing customers and offer the best rates to new customers.

Given the popularity of BBPD, a growing literature studying price discrimination in dynamic models of strategic interaction has emerged (see Esteves, 2014 and Fudenberg and Villas-Boas, 2006 for detailed surveys). Equilibrium outcomes in these models are dependent on 
specific modelling assumptions and diverge in their predictions regarding the impact of BBPD on prices and consumer welfare. For instance, market outcomes vary with assumptions regarding market dominance (e.g., Chen, 2008), consumer preferences (e.g., Chen and Pearcy, 2010), switching costs (e.g., Shaffer and Zhang, 2000; Chen, 1997) and customer heterogeneity (e.g., Shin and Sudhir, 2010; Gehrig et al., 2007). While theoretical models of strategic interaction are well developed in the literature; however, the empirical validation of theoretical predictions is limited (Amaldoss et al., 2008).

A gap between pricing theory and application has long been recognized (Oxenfeldt 1973). Ingenbleek and Lans (2013) contend that there is a difference between pricing strategy more commonly visible in markets and pricing practices which are internal to firms and little is known about their influence. The differences in observed price discrimination strategies across industries could indeed be the result of differences in managerial practice influenced by factors such as market structure. Through this study, we aim to reconcile differences in observed pricing behavior across industries by theoretically and empirically analysing the effect of market share on pricing strategies. We consider the competitive dynamics in markets where firms vary in terms of the size of their customer base and are able to price discriminate on the basis of customer's purchase history. More specifically, we address the following questions; how does inherited market share impact prices offered to existing and new customers? Are small firms more likely to offer loyalty discounts? Do large firms offer aggressive switching discounts? What are the profit implications of BBPD across market outcomes?

Based on our proposed model of static competition, in equilibrium, symmetric competitors will offer discounts to new customers, while asymmetric competition provides sufficient conditions for small firms to offer loyalty rewards. We find that aggressiveness in 
pricing (difference in price to new and existing customers) decreases when markets become more competitive and market dominance (large inherited market share) is positively correlated with aggressive customer poaching. We further test our predictions by conducting a controlled experiment. Through our empirical study we contribute to the growing literature on experimental validation of theoretical pricing models (e.g., Amaldoss et al., 2008). An experimental setting is particularly suited to our study ${ }^{1}$ as it allows us to control for confounding factors (e.g., strategic customer behavior, asymmetric information, and differences in costs of production) enabling us to determine the impact of causal factors in isolation and providing internal validity. Since detailed data on pricing are difficult to obtain, through a controlled experiment we not only replicate real world pricing scenarios but can also observe the pricing practices that emerge as a result of the strategic interaction and also investigate the factors that trigger divergence from our model predictions.

By analyzing the behavior of sufficiently incentivized experimental participants we confirm the significance of social preferences and market structure as moderators of BBPD. The results from our experimental study highlight that market structure is indeed a key factor that influences pricing practice. In line with our theoretical predictions, we find that firms with a priori small market share adopt a customer retention strategy whereby existing customers are offered a lower price compared to new customers. In contrast, when inherited market share is relatively high firms will adopt a poaching strategy with discounts encouraging rival's customers to switch. We further confirm that a customer retention strategy enables firms with small market share to increase not only market share but also increase profit, in contrast firms with an a priori large market share end up losing market share and profits due to the aggressive customer

\footnotetext{
${ }^{1}$ Experimental studies are increasingly being used to better understand competition and pricing in oligopolistic markets (e.g., Dufwenberg and Gneezy, 2000; Grether and Plott, 1984).
} 
poaching behavior. Hence, asymmetric markets would end up moving towards to a more symmetric outcome when BBPD is allowed as a customer retention strategy by small firms would enable them to profitably compete with the dominant player in the market.

The remainder of this paper is organized as follows: Section 2 presents an overview of the relevant literature, Section 3 presents the analytical model while Section 4 outlines the main hypothesis to be tested, Section 5 outlines the experimental procedure and design, Section 6 presents the findings of the experimental study and Section 7 presents a discussion of the key findings and policy implications.

\section{Literature Review}

Over the past decade, a diverse literature has emerged studying price discrimination in markets with customer recognition. A dominant theme in the literature is that customer recognition coupled with constant consumer preferences results in the intense competition to attract new customers through switching discounts, while consumer surplus is extracted from existing customers (e.g., Chen and Zhang, 2009; Pazgal and Soberman, 2008; Fudenberg and Tirole, 2000). However, practitioner perspective and academic literature diverge on whether current or new customers should be rewarded.

A few academic studies address this question and explore the necessary conditions for profitable loyalty rewards. For instance, Chen and Pearcy (2010) introduce price commitment and preference stochasticity to show that loyalty rewards can be profitable. Whereas Shin and Sudhir (2010) suggest that customer stochasticity and heterogeneity are pre-requisites for profitable customer retention strategies. Esteves (2014) shows how horizontally differentiated firms can offer retention strategies to customers likely to switch. 
While most studies consider price discrimination in symmetric markets, where each firm has equal market power to counter rival's pricing strategy, some studies also explore the outcome in asymmetric markets. For instance, Caillaud and De Nijs (2014) find that in equilibrium with infinitely lived symmetric duopolists, a pay to stay strategy or loyalty rewards may emerge for the firm which is unable to recognize its old loyal customers. Shafer and Zhang (2000) consider an asymmetric duopoly market and show that asymmetric switching costs are sufficient to make a customer retention strategy (better deals offered to existing customers than to new ones) profitable. Gehrig et al. (2012) also consider the role of inherited market share asymmetry on profits and consumer welfare in markets with BBPD. The static analysis of Gehrig et al. (2012) highlights that with asymmetric inherited market shares, the smaller firm offers lower prices to existing customers, resulting in a dilution of dominance, lower industry profits but increases consumer welfare, unless switching costs are too high. In contrast, Chen (2008) considers an asymmetric market in a dynamic setting, where the firm with the stronger brand eliminates competition by adopting an aggressive poaching strategy. Thus the literature highlights that both customer preferences, across time and firms' asymmetry can be important determinants of the pricing strategy to target at each group of consumers, i.e., loyalty rewards or customer poaching. In order to analyze the role of inherited market share on price discrimination, we focus on the sub-game analysis where first period market share is taken as given and we explore all possible second period equilibria. Our static second period analysis, illustrates the change in pricing behavior subject to symmetric and asymmetric market outcomes in the first period. Our static analysis is thus not only akin to the second period of Fudenberg and Tirole (2000) but our static analysis is in line with Shaffer and Zhang (2000) and Gehrig et. al. (2012) as it allows us to incorporate asymmetric customer preferences with both ex-ante product differentiation and ex- 
post switching costs $(t>0)$ which makes prices dependent on market share $(\theta)$. In the current model we have both ex-ante product differentiation and ex-post switching costs $(t>0)$ which makes prices dependent on market share $(\theta)$.

Such market dominance can result from a number of sources: first, asymmetry could emanate from horizontal differentiation due to differences in brand preferences where one firm is more preferred than the other. Inherited market dominance could also stem from one firm being an incumbent in the market or due to locational advantages where customers with strong preferences are located close to one firm. It should be further noted that the inherited market share asymmetries could emerge from both actual purchase behaviors in period 1 or as in Shaffer and Zhang (2000) from revealed preferences obtained from market research (e.g. surveys or purchase behavior of other related product categories). Second, the presence of transportation costs imply that the higher market share firm A has, the higher will be the cost of firm B's customers to switch to firm A's location. Hence, variations in market share can introduce asymmetries in the second period.

The difficulty in obtaining detailed pricing data at the industry level makes empirical validation of theoretical predictions difficult. Therefore, we conduct a controlled experiment to validate our theoretical predictions. Through our experimental study, we contribute to the existing literature on BBPD by not only testing the validity of theoretical predictions, while accounting for alternative explanations.

In doing so our paper also contributes to the experimental literature on pricing in competitive markets. There has been a long tradition of using experiments to study price competition (e.g., Amaldoss and He 2016; Lim and Ho, 2007; Morgan et al., 2006; Baye and 
Morgan, 2004; Dufwenberg and Gneezy, 2000; Smith, 1962). However, these studies focus on markets where customer recognition is not possible.

In the context of BBPD Mahmood (2014) experimentally examines the impact of customer characteristics (heterogeneity and preference stochasticity), on pricing in symmetric duopolistic markets in a dynamic two-period setting. In another study, Brokesova et. al. (2014) experimentally test the role of price pre-commitment for repeat buyers and find modest loyalty discounts. Our study differs from these studies as we present insights regarding the role of market structure on BBPD. We outline our stylized model and predictions in the next section.

\section{The Model}

Two firms, $\mathrm{A}$ and $\mathrm{B}$, produce an identical product with a marginal cost of $c$, which we set to zero in the subsequent analysis. The two firms compete across two periods, 1 and 2.

On the demand side, there is a population of consumers with mass normalized to 1 . In each period, each consumer wishes to buy a single unit either from firm A or B and is willing to pay at most $v$. The reservation value $v$ is sufficiently high so that the market is fully covered. In line with Fudenberg and Tirole (2000) the market is such that consumers have exogenous preferences for brands that are present from the start. The market is thus horizontally differentiated with consumer preferences are specified in the Hotelling-style linear market of unit length with firms positioned at the endpoints. A consumer brand preference parameter $\theta$ is uniformly distributed on $[0,1]$ and remains fixed over time. While extant research has modeled preferences as stochastic across time (e.g. Chean and Pearcy 2010), however, our focus is on the supply side dynamics that may arise as a result of market structure variations, therefore, we abstract from a condition where consumer preferences may be unstable. 
A consumer located at $x$ incurs total cost $p_{A}+t \theta$ if buys from firm $\mathrm{A}$ at the price $p_{A}$, and incurs total cost $p_{B}+t(1-\theta)$ if buys the unit from $B$ at the price $p_{B}$. Each consumer has a valuation $v$ for the product large enough to ensure complete market coverage. The utility of a consumer is defined as:

$$
v-p_{i}-t \theta
$$

Consumers can reveal information about their brand preferences through a variety of sources such as their period 1 purchase of A and B's products, purchase of similar products that may reveal a preference for firm A or B or through market research surveys. All these sources of revealed preference asymmetry are compatible with our framework. For ease of exposition we assume that consumers reveal brand preferences by their first period purchase decisions. Suppose that standard competition à la Hotelling allows firm A to attract a fraction of $\theta$. Firm $A$ 's turf is the interval $[0, \theta]$ while firm $B$ 's turf is the remaining $[\theta, 1]$ In period 2 each firm is able to recognize its own previous customers and the rival's ones.

\section{Sub-game equilibrium analysis}

While there is value in studying the dynamics of two period markets, we feel that BBPD is practiced most often in mature markets like subscription, utilities etc. where firms have knowledge of customer preferences. In a two period dynamic model of BBPD forward-looking customers and firms would act strategically in Period 1 based on the expectations of the game played in the second period, and in most cases with horizontal differentiation there emerges a symmetric outcome in the first period with both firms offering the same price. Since our objective is to analyze the outcomes in markets where demand asymmetries exist we only present a static second period analysis where first period market shares are exogenous. 
In our sub-game both firms have the ability to determine the identity of their customers i.e, both firms can identify whether a customer purchased from A in period 1(existing customer) or $\mathrm{B}$ (potential customers). ${ }^{2}$ Based on this information both firms can simultaneously choose a price to its loyal customers (either existing customers or customers that have revealed their preference for firms i) $p_{i}^{o}$ and a price to the new customers $p_{i}^{n}, i=A, B$. hence, the firms now compete over two distinct groups of customers in period 2, loyal and new customers. We first consider the competition in firm A's loyal/existing customer base $[0, \theta]$. Let $p_{A}^{o}$ represent firm A's price to its loyal customers and firm B will offer price $p_{B}^{n}$ as it will try to attract potential new customers from A's existing customer group.

The indifferent consumer between buying again from $\mathrm{A}$ at price $p_{A}^{o}$ and switching to $\mathrm{B}$ and pay $p_{B}^{n}$ is located at $\theta_{A}$ such that

$$
\begin{aligned}
& p_{A}^{o}+t \theta_{A}=p_{B}^{n}+t\left(1-\theta_{A}\right) \\
& \theta_{A}=\frac{1}{2}+\frac{p_{B}^{n}-p_{A}^{o}}{2 t}
\end{aligned}
$$

Consumers in the interval $\left[\theta_{A}, \theta\right]$ will switch from A to B. similarly, in B's turf $[\theta, 1]$, the ineifferent customer located at $\theta_{\mathrm{B}}$ wil be indifferent between staying with $\mathrm{B}$ and switching to $\mathrm{A}$ as follows:

$$
\begin{aligned}
& p_{B}^{o}+t\left(1-\theta_{B}\right)=p_{A}^{n}+ t \theta_{B} \\
& \theta_{B}=\frac{1}{2}+\frac{p_{B}^{o}-p_{A}^{n}}{2 t}
\end{aligned}
$$

Thus, consumers in the interval $\left[\theta, \theta_{B}\right]$ switch from $\mathrm{B}$ to $\mathrm{A}$ and consumers in the interval $\left[\theta_{B}, 1\right]$ remain loyal to B. In A's turf, each firm solves the following problem

$$
\underset{p_{A}^{o}}{\operatorname{Max}}\left\{p_{A}^{o}\left(\frac{1}{2}+\frac{p_{B}^{n}-p_{A}^{o}}{2 t}\right)\right\}
$$

\footnotetext{
${ }^{2}$ Alternatively, the location of customers could also reveal their preferences for firms A and B.
} 


$$
\underset{p_{B}^{n}}{\operatorname{Max}}\left\{p_{B}^{n}\left(\theta-\frac{1}{2}-\frac{p_{B}^{n}-p_{A}^{o}}{2 t}\right)\right\}
$$

Similarly, in firm B's turf each firm solves

$$
\begin{aligned}
& \underset{p_{A}^{n}}{\operatorname{Max}}\left\{p_{A}^{n}\left(\frac{1}{2}+\frac{p_{B}^{n}-p_{A}^{o}}{2 t}-\theta\right)\right\} \\
& \underset{p_{B}^{o}}{\operatorname{Max}}\left\{p_{B}^{o}\left(1-\frac{1}{2}-\frac{p_{B}^{n}-p_{A}^{o}}{2 t}\right)\right\}
\end{aligned}
$$

Proposition 1. Given the ability to price discriminae between exiting and new custoers, in the equilibiurm prices dependent on the baseline market share can be defines as:

Case I: $\quad \theta \leq \frac{1}{4}$

$$
\begin{gathered}
p_{A}^{o}=c+\frac{t(3-6 \theta)}{3} ; p_{A}^{n}=c+\frac{t}{3}(3-4 \theta) \\
p_{B}^{o}=c+\frac{t(3-2 \theta)}{3} ; p_{B}^{n}=0 \\
\text { with } p_{A}^{o}<p_{A}^{n} \text { and } p_{B}^{n}<p_{B}^{o}
\end{gathered}
$$

The firm with the less preferred brand offers(low inherited market share) lower prices to existing customers

The resulting Period 2 equilibrium profits are.

$$
\begin{gathered}
\pi_{A}^{2}=\frac{t(3-6 \theta)}{3} \theta+\frac{1}{18} t(4 \theta-3)^{2}, \\
\pi_{B}^{2}=\frac{t(3-2 \theta)^{2}}{18} .
\end{gathered}
$$

Case II: $\frac{1}{4} \leq \theta \leq \frac{3}{4}$

$$
p_{A}^{o}=\frac{t(2 \theta+1)}{3} \text { and } p_{A}^{n}=\frac{t(3-4 \theta)}{3}
$$




$$
\begin{gathered}
p_{B}^{o}=\frac{t(3-2 \theta)}{3} \text { and } p_{B}^{n}=\frac{t(4 \theta-1)}{3} \\
\text { with } p_{A}^{o}>p_{A}^{n} \text { and } p_{B}^{o}>p_{B}^{n}
\end{gathered}
$$

With sufficiently symmetric brand preferences (similar inherited market share) both firms offer lower prices to potential new customers and higher prices to existing customers.

At an interior solution it is always the case that

$$
\pi_{A}^{2}=p_{A}^{o} \theta_{A}+p_{A}^{n}\left(\theta_{B}-\theta\right)
$$

which equals:

$$
\pi_{A}^{2}=t \frac{10 \theta^{2}-10 \theta+5}{9}
$$

Similarly, it is straightforward to obtain that firm B's second-period profit:

$$
\pi_{B}^{2}=t \frac{5+10 \theta^{2}-10 \theta}{9}
$$

hence, both firms make the same profit.

Case III: $\theta \geq \frac{3}{4}$ :

$$
\begin{gathered}
p_{A}^{o}=\frac{t(1+2 \theta)}{3} ; p_{A}^{n}=0 \\
p_{B}^{o}=\frac{t(6 \theta-3)}{3} ; p_{B}^{n}=\frac{1}{3} t(4 \theta-1) \\
\text { with } p_{A}^{o}>p_{A}^{n} \text { and } p_{B}^{o}<p_{B}^{n}
\end{gathered}
$$

The firm with the more preferred brand (large inherited market share) offers lower prices to potential new customers and high prices to existing customers. The gap in prices to new and existing customers $\left(p_{A}^{o}-p_{A}^{n}\right)$ is greater than the gap in prices in Case II. 
and second-period profits are

$$
\begin{gathered}
\pi_{A}^{2}=\frac{t(1+2 \theta)^{2}}{18} \\
\pi_{B}^{2}=\frac{t(6 \theta-3)(1-\theta)}{3}+\frac{1}{18} t(4 \theta-1)^{2}
\end{gathered}
$$

Proof. See the Appendix

\section{Comparison of cases}

We briefly summarize the main comparative statics of the model in Table 1.

In Case I, the firms with the small market share sets prices that are lower for the existing customers and higher for the new customers. By adopting a strategy favoring existing customers the less preferred firm ensures that customers are not poached away by the more preferred firm with the larger market share. Secondly, by keeping the price level high for the potential new customers the firms can make up for lost profit by avoiding steep discounts to customers who switch.

In Case II, given rational buyers both firms have equal incentives to encourage customer to switch. Therefore, in equilibrium in the second period both forms offer the same level of discount to new customers and attempt to retain existing customers. Resulting in a third of the market switching in equilibrium See Appendix A).

Finally, in Case III the dominant (i.e., more preferred) firm attempts to make profits by charging high prices to its existing customers which is higher than the price charged by the small rival to its existing customers, as a consequence we observe no customer switching from the small firm's turf and customers switch from the dominant firm's turf. In light of the aggressive pricing $\left(p_{A}^{o}-p_{A}^{n}\right)$ behavior of the dominant first in the second period both the dominant firms and the 
small firm make the same amount of profit.

Overall we observe that pricing aggressiveness increases in first period market share, with the game between the prices offered to new and existing customers increasing in the first period inherited market share. In addition, this aggressiveness can result in loss of market share in asymmetric markets where by adopting a customer retention strategy the small firm can regain customers and make profit equal to the dominant rival.

\section{Experiment}

Consistent with our model we test for manipulations of the market structure $\left(\theta_{1}=\right.$ $\left.\frac{1}{4}, \frac{1}{2}, \frac{3}{4}\right)$, respectively, small asymmetric, symmetric, and dominant asymmetric). Our objective is to understand the firms' pricing behavior when purchase history data is available. Similar to previous studies on strategic pricing behavior in spatial models (e.g. Amaldoss and He, 2016; Selten and Apesteguia 2005), our focus is on the supply side of the market and hence we abstract from the demand side of the market. While we could introduce nuances in consumer behavior, it is beyond the focus of our study as we are interested in understanding the strategic reaction of firms to differences in market share given that consumers are rational utility maximizers.

Hence, participants played the role of firms and make pricing decisions when they have knowledge of existing and new customers. The parameters used in the experiment were $c=100$, $v=2000$ and $t=200$. The parameters were chosen to ensure clear separation in predicted prices. The equilibrium price predictions are summarized in Table 1.

\section{Stimuli and Pretest}


We conduct a pretest $(n=120)$ using a between subjects' design where we gave participants the descriptions of the three market share scenarios and asked participants about their willingness to offer discounts to existing and new customers and whether their firm had an advantage in terms of profitability over the rival. In addition, we also made participants set the prices for existing and new customers.

We performed a $3 \times 1$ between-participant ANOVA with small, symmetric and large market share as the fixed factors, and discount to new customer as the dependent variable. Specifically, the greater the market share the greater the propensity to offer discounts to new customers $(\mathrm{F}(2$, $120)=4.92, p<.010)$ however, there were no significant differences in the propensity to offer discounts to existing customers $(\mathrm{F}(2,120)=1.26, \mathrm{p}=0.2887)$ Similarly, for impressions of profitability across the three treatments we observe differences in perceptions regarding profitability of firms across markets $(\mathrm{F}(2,117)=5.69, p<.005)$. We also asked participants to enter prices for new and existing customers in across two rounds and again we find differences in the actual prices entered for existing customers and new customers $(p<0.01)$.

The variation in responses across the three treatments gives us confidence that the manipulation of Period 1mark structure were acknowledged by participants. Finally, as a further validation test to ensure participants understood the relation between demand and price in the context of our model, we gave the participants a pricing task as a monopolist. We asked participants to respond how demand would change if we increased the price. $80 \%$ of the respondents selected the correct option giving us further confidence that participants were aware of the tradeoff between demand and price.

Study 1: Method and Measures 
A total of 300 participants took part in a between-subjects design with 100 participants assigned to each treatment following our theoretical model (small market share, symmetric market share, and dominant market share).

Participants were recruited online from Mechanical Turk an online crowd sourcing market place commonly used for experimental studies (Gosling et al., 2004). The use of such online subject pools ensures internal validity due to the lack of interaction between experimenter and subjects resulting in limited opportunities for experimenter bias (Orne, 1962) or subject cross talk due to the limited interaction between subjects (Edlund et al., 2009). The reliability and validity of the data obtained from Mturk samples is well-established, and Mturk samples tend to be representative of the general population in terms of age, race, and gender ((for discussions, see Berinsky et al., 2012; Buhrmester et al., 2011; Paolacci et al., 2010). Indeed, participants recruited for our study belonged to diverse backgrounds including managerial and business professions.

We are thus assured that our MTurk sample is more representative of managers and no less sophisticated than the student subjects used in several of the previous studies of firm behavior (e.g., Brokesova et al., 2014; Lim and Ham, 2013; Holt 1994). Further, according to Plott (1991) in the context of market experiments the theory of market equilibrium, if true, should predict behavior in a laboratory market just as it should predict behavior on the London Stock Exchange. Hence, we are confident regarding the external validity of our experiments.

Participants were shown detailed instructions regarding the rule of the game (detailed instructions can be found in Appendix B). Participants were informed that they were taking part in a pricing game where they would set prices for a firm in a competitive market with the objective of maximizing profits. They were further informed that they would set prices against a 
computerized opponent playing the profit maximizing strategy. Following extant experimental research (e.g. Amaldoss and He, 2016; Mahmood, 2014; Orzen and Sefton, 2008; Selten and Apesteguia, 2005) we informed participants that firms are horizontally differentiated such that the firms are located at either end of a $200 \mathrm{~km}$ market with customers evenly distributed along the street ( 1 customer per $\mathrm{km})$. The location of buyers is crucial in our design and represents their intrinsic preference for a particular seller as due to the traveling costs buyers prefer to go to the store located near to them.

Participants were further informed that customers are utility maximizers who will purchase from the firm that minimizes their total expense and are likely to switch between firms if they find a better deal. We use the demand function derived from our consumer model to program robot buyers to play the role of consumers (see Selten and Apesteguia, 2005; Amaldoss and He, 2016 for similar designs).

The game started in Period 2. Sellers (participants) were given information on the outcome of the market in Period 1 and were asked to set Period 2 prices for existing customers (who purchased from the seller in period 1) and potential new customers (who purchased from the competitor in period 1).

After setting prices for the two customer types, participants were shown their Period 2 profits along with the corresponding market share, after which the round was complete. To familiarize themselves with the rules of the game Participants were given the option to play multiple trial rounds against a computer-simulated competitor before entering the market. Once participants had understood the rules of the game they proceeded to make actual pricing decisions. Participants played 12 rounds with a new market in every round. Participants were not made aware of the number of rounds ensuring that the equilibrium did not unravel via backward 
induction. For the purpose of analysis, we retain the observations from the last 10 rounds of the experiment.

Experimental sessions lasted around half an hour. At the end of the game, participants received a bonus in line with the profit earned in the game. We are confident that MTurk workers were sufficiently motivated especially since the bonus was greater than the fixed payment. On average participants earned $\$ 4.37$ which is quite high for MTurk participants).

We dropped observations that were completed in haste as measured by the time spent on the study, leaving us with 980 observations for the small market share condition, 970 for the symmetric market share and 930 for the large market share condition.

Following prior research on fairness and reciprocity that links perceptions with behavior in experimental settings (Glaeser and Souter, 2000; Karlan, 2005) we also questioned subjects about their attitudes on reciprocity, trust and fairness perceptions (see Appendix B).

\section{Results}

\section{Impact of Market share on Prices}

We first present a comparison between theoretical predictions and experimental prices in Table 2. Comparison of the price to new and existing customers reveals that the participants react to the existence of the two groups of customers and engaged in BBPD when given the option across all three treatments. Figure 1 provides a summary of the prices offered to existing and new customers. Figure 1 and Table 2 show that in line with our prediction, for the small firm condition the price to new customers is higher than the price set for existing customers $(t=-$ $1.52 *, p<0.1)$, while symmetric market share $\left(t=5.75^{* * *}, p<0.001\right)$ results in customer poaching with higher prices to existing customers compared to potential new customers. In this 
case, we find that our experimental results are in line with our model predictions and those in the BBPD literature (e.g. Fudenberg and Tirole, 2000) as well as with results obtained in other experimental studies on BBPD (e.g. Mahmood, 2014). Finally, for the large inherited market share $\left(t=6.55^{* * *}, p<0.001\right)$ we also observe that Dominant firms also adopt a customer poaching strategy (whereby participants further expand market share by attracting the smaller rival's customers and make up lost profit by charging higher prices to the existing customer base. Further, comparison of the propensity to offer loyalty discounts across market share treatments reveals that compared to the symmetric case in the small market share condition loyalty discounts are significantly higher $\left(z=14.207^{* * *}, p<0.001\right)^{3}$ while under the large market share the propensity to offer loyalty rewards is significantly lower $\left(z=1.95^{* *}, p<0.06\right)^{4}$. Hence, lack of inherited market share provides a sufficient condition for loyalty rewards.

We further note that the difference in prices to existing and new customers (aggressiveness) also varied across market structure conditions. In line with our predictions, aggressiveness in pricing increased with market share, i.e. small firms were the least aggressive while large firms were the most aggressive (see Figure 3). However, they were less aggressive in the pricing behavior than theory predicted.

Further comparing the prices with theoretical predictions we note that while prices were directionally in line with our predictions, experimental prices were consistently higher than the equilibrium predictions. For instance, prices for new customer across small firms $(t=5.88 * * *$, $p<0.01)$, symmetric firms, $\left(t=6.88^{* * *}, p<0.01\right)$ and large firms $(t=12.49 * * *, p<0.01)$. all set prices higher than equilibrium. Similarly, with the exception of the large firms $(t=0.81$,

\footnotetext{
${ }^{3}$ Based on two sample Wilcoxon rank sum test

${ }^{4}$ Based on two sample Wilcoxon rank sum test.
} 
$p>0.21$ ), the price offered to existing customers is significantly higher than the equilibrium prediction for both the small firm $\left(t=9.06^{* * *}, p<0.01\right)$ symmetric firm $(t=3.07 * * *, p<0.01)$ scenarios. This indicates that subjects were mindful of the profit implications and did not offer lower prices at the expense of market share

Other pricing such as Breksolova et al. (2014) and Baye and Morgan (2004) also find that under experimental conditions participants select higher prices than the equilibrium counterparts. Amaldoss et al. (2008) note that the divergence between theoretical predictions and experimental outcomes can also be due to individual-level heterogeneity. Our multiple round design mitigates some of the individual heterogeneity by allowing responses to converge (Camerer 2003).

Figure 3 summarizes the average prices offered by participants across rounds. Considering first the small market share scenario, we observe that across rounds prices to existing customers remained lower than the price for new customers, however, the prices are consistently higher than the model predictions. For the symmetric treatment the existing prices are closer to the point prediction of the model, while the new prices are much higher than the model prediction, however, across all rounds we observe participants engaging in customer poaching. Finally, for the large market share condition, we observe that the price to existing customers does not significantly depart from the model prediction, however, the price to new customers is significantly higher than the cost across all rounds.

Another possible explanation for the deviation in the results could be a be a product of social preferences like the participants own perceptions of fair behavior, warranting an individual level analysis. For instance, Kahneman et al. (1986) find that fairness concerns restrict profit maximizing behavior, similarly experimental subjects' perceptions of fairness have been known to influence behavior. (Glaeser and Souter, 2000; Karlan, 2005). In our context rewarding or 
extracting surplus form existing customers could be a function of sellers' perception of trust and reciprocity.

Prior research has shown that surveys are a good way of eliciting participants attitudes and social preferences which in some instances may also be predictive of behavior (see Maximiano 2012 for a detailed review). Therefore, we ask participants whether they would reward good behavior of others and whether they expect their good behavior to be rewarded on a five point Likert scale. We then combine participants' responses to these questions as an equally weighted index to create our reciprocity variable. The underlying premise being that participants who value trust and reciprocity will reward good behavior (in our context customer loyalty) with discounts and will expect such discounts to result in good behavior form customers by not switching to the rival.

So far we have observed the average prices, we now present an individual level analysis of the impact of market share on the pricing strategy accounting for observed heterogeneity in social preferences such as reciprocity, controls for repeated play via experimental round dummies and finally the random effects specification controls for unobserved heterogeneity in participant behavior.

First, to determine the impact of market share on prices for existing customers we estimate a logit model with the dummy of loyalty discount (New Price > Existing Price) as the dependent variable and treatment dummies, reciprocity index and experimental round dummies as treatment variables, as follows:

$$
\text { Loyalty }_{i}=\beta_{1}+\beta_{2} 25 \%+\beta_{3} 75 \%+\beta_{4} \text { Reciprocity }+\sum_{t=1}^{10} \beta_{i t} r_{t}+\varepsilon_{i} \text {, }
$$

where $i$ denotes experiment participant and $t$ denotes experimental round. 
After controlling for observed and unobserved heterogeneity and learning across rounds we find that lack of market share is a sufficient condition for loyalty discounts. The small firm dummy has a significant positive impact on the propensity to offer loyalty discounts $(p<0.01)$ while the dummy for the large firm has a significant negative impact on the propensity to reward existing customers with loyalty discounts $(p<0.01)$ (see column 1 Table 3 ).

According to our theoretical predictions, the aggressiveness in prices (New Price Existing Price) varies with market share, such that the difference between new and existing customers increases in market share, with the large firms setting the most aggressive prices. We next analyze the differences in prices offered to existing and new customer. We regress the aggressiveness (New Price - Existing Price) on treatment dummies, reciprocity index and experimental round dummies as follows:

$$
\text { Aggressiveness }_{i}=\alpha_{1}+\alpha_{2} 25 \%+\alpha_{3} 75 \%+\alpha_{4} \text { Reciprocity }+\sum_{t=1}^{10} \beta_{i t} r_{t}+\mathcal{E}_{i},
$$

where $i$ denotes experiment participant and $t$ denotes experimental round.

The results are summarized in Table 3.

Looking at the determinants of differences in prices to new and existing customers we find that consistent with our model prediction higher market share results in more aggressive pricing behavior as the dominant firms extract surplus from existing customer while offering discounts to attract new customers in response to the strategy of the dominant firm the small firms attempt to retain their existing customer by offering loyalty rewards, in addition since large firms charge high prices to their existing customers, small firms only have to offer a small discount to encourage customer to switching.

\section{Impact of Market share on Profits}

Finally, we consider the impact of market structure concerns on second-period profits. 
Figure 4 shows the profit across treatments. In line with the intuition of our model, we observe that the retention strategy of the small firms pays off compared to the poaching strategy of the large firm. It should also be noted that though the profit is much higher than equilibrium from the $25 \%$ and $50 \%$ conditions primarily due to the higher than equilibrium prices. for the $75 \%$, we observe that the profit is closer to the theoretical prediction as the experimental prices were closer to the theoretical predictions (see Figure 3).

We also perform an individual level analysis of Period 2 profit. We regress the profit on dummies for market share whilst controlling for participant's social preferences and rounds. That is we estimate the following model:

$$
\text { Profit }_{i}=\beta_{1}+\beta_{2} 25 \%+\beta_{3} 75 \%+\beta_{4} \text { Reciprocity }+\sum_{t=1}^{10} \beta_{i t} r_{t}+\varepsilon_{i},
$$

where $i$ denotes experiment participant and $t$ denotes experimental round.

Based on Figure 4 and the column 3 of Table 3, we can see that for the asymmetric treatment a customer retention strategy pays off in terms of high profits while for the large firms the aggressive poaching strategy results in lower profits.

\section{Discussion}

Behavior-based price discrimination has been extensively studied in recent years and a wide body of theoretical research has emerged. However, there is limited empirical validation. We contribute to the literature on BBPD by exploring the impact of inherited market share on pricing behavior in markets with customer recognition and providing empirical validation of our predictions with a controlled experiment.

The objective of our study is to explore the competitive dynamics in mature markets that vary in terms of the inherited market share and where purchase history of consumers is 
observable. Therefore, we focus on the second period of Fudenberg and Tirole's (2000) seminal model of BBPD and abstract form first period competition by introducing Period 1 market share exogenously. Abstracting from the first period game considerably simplifies the model, making it more suitable for experimental validation. While a Nash equilibrium of the entire game would have warranted the asymmetric outcomes as off the equilibrium path, however, in reality, markets are mostly asymmetric. Therefore, by considering asymmetry as differences in market share makes our study relevant to a number of common market scenarios that define many industries (e.g., subscription markets, retail, insurance, telecommunications, and utilities), where some firms dominate the market while others have limited market share.

Based on our simplistic model, when baseline market share is sufficiently low (i.e. $\theta \leq \frac{1}{4}$ ) the small firms will engage in a customer retention strategy whereby, existing customers will be charged lower prices compared to the price offered to potential new customers. In contrast, firms with large inherited markets share (i.e. $\theta>\frac{1}{4}$ ) will engage in a customer poaching strategy, offering discounts to potential new customers and making a profit by charging higher prices to existing customers.

We then test our theoretical predictions via controlled experiments with incentivized participants. Through a controlled experiment we not only replicate real world pricing scenarios but can also observe the strategic behavior of experimental participants. An experimental setting is particularly suited to our study ${ }^{5}$ as it allows us to control for confounding factors (e.g., strategic customer behavior, asymmetric information, and differences in costs of production) enabling us to determine the impact of causal factors in isolation and providing internal validity. 
Our findings support our theoretical predictions; customer recognition results in customer poaching when market share is sufficiently high and lack of inherited market power results in the small firm participants offering loyalty discounts. In addition, the aggressiveness in pricing also varies across inherited market share, with small firms offering the least difference in prices and the dominant firms offering the largest gap in prices to existing and new customers.

From a policy perspective, BBPD is unlikely to raise antitrust concerns as a priori asymmetric markets become more competitive when firms have the ability to engage in BBPD. Our experiment results show that profits were lower for the dominant firms when they engage in aggressive customer poaching compared to the small firms who increased profits and market share by adopting a customer retention strategy. Hence, our findings confirm that the use of aggressive poaching to increase market share can be sub-optimal (Armstrong and Green, 2007).

Furthermore, the relatively small difference in prices for existing and new customers can also improve customer welfare, as feelings of customer dissatisfaction arising from price comparisons amongst customers may be low when there are a greater number of smaller firms in the market. Indeed, in a world where internet forums, brand communities, social networks facilitate social comparisons enabling customers to easily detect whether they paid more or less than a comparative reference (Bickart and Schindler, 2001), differences in prices paid by customers can lead to feelings of inequality (Xia et al., 2004), which could result in long-term customer dissatisfaction. Hence, markets with several smaller firms might be more beneficial for customer welfare compared to large firms. However, formal tests of these effects are beyond the scope of the current study.

Further our experimental setup shows that social preferences of sellers are important factors that can help explain the preference for loyalty rewards and price aggressiveness. Future 
research can incorporate managers' social preferences in models of strategic interaction to better explain observed pricing behavior. Future research can also use professional pricing experts as subjects to provide greater external validity. Indeed, a one-shot pilot study $(n=45)^{6}$ with participants recruited via online professional pricing societies revealed differences in BBPD across market structure, with participants with large inherited market share engaging in customer poaching while participants with a small inherited market share did not price discriminate between existing and new customers $(z=2.44, p<0.02)^{7}$.

There are however, certain limitations of our study. We contend that inherited market share is the source of asymmetry. However, there could be other sources of asymmetry such as cost and quality differences. Further, asymmetry could also emerge from the ability to recognize customers, more established firms may have the ability to recognize customers while new entrants may not have access to such information, such an asymmetry in customer recognition could significantly influence the outcome of BBPD. Future research can explore these areas in more detail. Another limitation of our setup is that we consider customers with constant preferences, in real subscription markets the preferences of customers are volatile and customers may act strategically. Future research should incorporate such behavioral complexities and use real buyers.

Controlled experiments are particularly useful in comparing behavior across models of strategic interaction, for this reason experimental studies are increasingly being used to better

\footnotetext{
${ }^{6}$ To accommodate the busy schedule of working professionals we conducted all experimental sessions online. ${ }^{6}$ Participants were sent emails with instructions regarding the competitive scenario and the rules of the game. Participants were informed that they were taking part in a two period game with one (three) competitors and their primary task was to set prices in each period to maximize profits. Participants were informed that 2,000 customers were evenly distributed across the 20-mile market with 100 customers at each unit interval.

${ }^{7}$ Based on the Wilcoxon signed rank test
} 
understand competition and pricing in oligopolistic markets (e.g. Amaldoss and He, 2016; Dufwenberg and Gneezy, 2000). Experimental validation is particularly useful in the context of models of behavior based price discrimination, where theory is well developed but sensitive to modeling assumptions and the question is not whether assumptions are right or wrong, rather which features explain real world pricing strategies. We hope this study will encourage further interest in experimental validation of models of strategic interaction. 


\section{References}

Amaldoss, W., \& He, C. (2016). Does informative advertising increase market price? An experimental investigation. Customer Needs and Solutions, 3(2), 63-80.

Amaldoss, W. and Jain, S. (2008). Research note-trading up: A Strategic Analysis of Reference Group Effects. Marketing Science, 27(5), 932-942.

Anderson, E.T., Fitzsimons, G.J. and Simester, D. (2006). Measuring and mitigating the costs of stockouts. Management Science, 52(11), 1751-1763.

Armstrong, J. S., and Green, K. C. (2007). Competitor-oriented objectives: The myth of market share. International Journal of Business, 12, 1.

Baye, M.R., and Morgan, J. (2004). Price Dispersion in the lab and on the Internet: Theory and evidence. RAND Journal of Economics, 449-466.

Berinsky, A. J., Huber, G. A., \& Lenz, G. S. (2012). Evaluating online labor markets for experimental research: Amazon.com's Mechanical Turk. Political Analysis, 20(3), 351-368.

Bickart, B., and Schindler, R.M. (2001). Internet forums as influential sources of consumer information. Journal of Interactive Marketing, 15(3), 31-40.

Big Data Zone (2016). How Amazon uses its own cloud to process vast, multidimensional datasets. [Available at: https://dzone.com/articles/big-data-analytics-delivering-businessvalue-at-am], Accessed 15th May 2017.

Bolton, L.E., Warlop, L. and Alba, J. W. (2003). Consumer perceptions of price (un) fairness. Journal of consumer Research, 29(4), 474-491.

Brokesova, Z., Cary,D., and Jana, P. (2014). Experimenting with purchase history based price discrimination. International. Journal of Industrial Organization, 37, 229-237.

Buhrmester, M., Kwang, T., \& Gosling, S. D. (2011). Amazon's Mechanical Turk a new source of inexpensive, yet high-quality, data? Perspectives on Psychological Science, 6(1), 3-5.

Caillaud, B., \& De Nijs, R. (2014). Strategic loyalty reward in dynamic price discrimination. Marketing Science, 33(5), 725-742.

Chen, Y. (1997). Paying Customers to Switch. Journal of Economics and Management Strategy, $6,877-897$.

Chen, Y. and Zhang, Z. J. (2009). Dynamic targeted pricing with strategic consumers. 
International Journal of Industrial Organization, 27(1), 43-50.

Chen, Y. (2008). Dynamic price discrimination with asymmetric firms. The Journal of Industrial Economics, 56(4), 729-751.

Chen, Y. and Pearcy, J. (2010). Dynamic pricing: when to entice brand switching and when to reward consumer loyalty. Rand Journal of Economics, 41, 674-685.

Deksnyte, I., And Lydeka, Z. (2012). Dynamic pricing and its forming factors. International Journal of Business and Social Science, 3(23).

Dufwenberg, M., and Gneezy, U. (2000). Price competition and market concentration: an experimental study. International Journal of Industrial Organization, 18(1), 7-22.

Edlund, J.E., Sagarin, B.J., Skowronski, J.J., Johnson, S.J. and Kutter, J. (2009). Whatever happens

in the laboratory stays in the laboratory: The prevalence and prevention of participant crosstalk. Personality and Social Psychology Bulletin, 35, 635--642.

Esteves, R.B, Liu, Q. and Shuai, J. (2016). Behavior-based price discrimination in a multidimensional preferences market. Working paper, NIPE WP 04/2016WP.

Esteves, R. B. (2014a). Price discrimination with private and imperfect information. The Scandinavian Journal of Economics, 116 (3), 766-796.

Esteves, R.B. (2014b). Behaviour-Based Price discrimination with retention offers. Information Economics and Policy, 27, 39-51.

Esteves, R. B. (2009). Customer poaching and advertising. The Journal of Industrial Economics, 57(1), 112-146.

Fischbacher, U., Fong, C.M. and Fehr, E. (2003). Fairness and the power of competition. Institute for Empirical Research in Economics, University of Zurich.

Fudenberg, D., and Tirole, J. (2000). Customer poaching and brand switching. RAND Journal of Economics, 634-657.

Gehrig, Thomas, Oz Shy, and Rune Stenbacka. (2012). A welfare evaluation of history-based price discrimination. Journal of Industry, Competition and Trade 12(4), 373-393.

Gehrig, T., Shy, O., \& Stenbacka, R. (2011). History-based price discrimination and entry in markets with switching costs: a welfare analysis. European Economic Review, 55(5), 732-739.

Gelbrich, K. (2011). I have paid less than you! The emotional and behavioral consequences of advantaged price inequality. Journal of Retailing, 87(2), 207-224. 
Glaeser, E., L. D. S. J. and Souter, C. (2000). Measuring trust. Quarterly Journal of Economics, $115,811-846$.

Gosling, S.D., Vazire, S., Srivastava, S. and John, O.P. (2004). Should we trust web-based studies? A comparative analysis of six preconceptions about internet questionnaires. American Psychologist, 59(2), 93.

Ingenbleek, P. T., \& Van der Lans, I. A. (2013). Relating price strategies and price-setting practices. European Journal of Marketing, 47(1/2), 27-48.

Kahneman, D., Knetsch, J. L., and Thaler, R. (1986). Fairness as a constraint on profit seeking: Entitlements in the market. The American Economic Review, 728-741.

Karlan, D. (2005). Using experimental economics to measure social capital and predict financial decisions. American Economic Review, 20, 1688--1699.

Mahmood A. (2014). How do customer characteristics impact behavior-based price discrimination? An experimental investigation. Journal of Strategic Marketing, 22(6), 530-547.

Maximiano, S. (2012). Measuring reciprocity: Do survey and experimental data correlate. Krannert School of Management Working Paper). West Lafayette: Krannert School of Management, Purdue University.

Morgan, J., Orzen, H., \& Sefton, M. (2006). An experimental study of price dispersion. Games and Economic Behavior, 54(1), 134-158.

Lim, N., \& Ham, S. H. (2013). Relationship organization and price delegation: An experimental study. Management Science, 60(3), 586-605.

Lim, N., \& Ho, T. H. (2007). Designing price contracts for boundedly rational customers: Does the number of blocks matter? Marketing Science, 26(3), 312-326.

Orne, M. T. (1962). On the social psychology of the psychological experiment: With particular reference to demand characteristics and their implications. American Psychologist, 17(11), 776.

Oxenfeldt, A. R. (1973). A decision-making structure for price decisions. The Journal of Marketing, 48-53.

Özer, Ö. and Phillips, R. (2012). The Oxford handbook of pricing management. Oxford University Press.

Paolacci, G., Chandler, J. and Ipeirotis, P.G. (2010). Running experiments on amazon mechanical turk. Judgment and Decision Making, 5(5), 411-419. 
Pazgal, A. and Soberman, D. (2008). Behavior-based discrimination: Is it a winning play, and if so, when? Marketing Science, 27(6), 977-994.

Plott, C. R. (1991). Will economics become an experimental science?. Southern Economic Journal, 901-919.

Shaffer, G. and Zhang, Z. J. (2000). Pay to switch or pay to stay: Preference-based price discrimination in markets with switching sosts. Journal of Economics and Management Strategy, 9(3), 397-424.

Shin, J., and Sudhir, K. (2010). A customer management dilemma: When is it profitable to reward one's own customers? Marketing Science, 29(4), 671-689.

Smith, V. L. (1962). An experimental study of competitive market behavior. The Journal of Political Economy, 70(2), 111-137.

Xia, L., Monroe, K. B. and Cox, J.L. (2004). The price is unfair! A conceptual framework of price fairness perceptions. Journal of Marketing, 68(4), 1-15. 


\section{List of Tables}

Table 1 Comparison of Prices Across Treatments

\begin{tabular}{llll}
\hline Period 1 Market share & $\theta_{1}=\frac{1}{4}$ & $\theta_{1}=\frac{1}{2}$ & $\theta_{1}=\frac{3}{4}$
\end{tabular}

\begin{tabular}{lccc}
\hline Existing Price $\left(\boldsymbol{p}_{A}^{\boldsymbol{o}}\right)$ & 200 & 233.33 & 266.67 \\
New Price $\left(\boldsymbol{p}_{A}^{\boldsymbol{n}}\right)$ & 233.33 & 166.67 & 100
\end{tabular}

Existing Price $\left(p_{B}^{o}\right)$

$\begin{array}{ccc}266.67 & 233.33 & 200 \\ 100 & 166.67 & 233.33\end{array}$

New Price $\left(p_{B}^{n}\right)$

$169.44 \quad 155.56 \quad 169.44$

$\begin{array}{llll}\text { A's Period 2 Profit }\left(\boldsymbol{\pi}_{\mathbf{A}}^{\mathbf{2}}\right) & 169.44 & 155.56 & 169.44 \\ \text { B's Period } 2 \text { Profit }\left(\boldsymbol{\pi}_{\mathbf{A}}^{\mathbf{2}}\right) & 169.44 & 155.56 & 169.44\end{array}$

Note: Model predictions are based on the following parametrization: Model prediction $t=200, v=2000, c=100$

Table 2 Comparison of Prices across Treatments

$\begin{array}{lll}\text { Market share } \quad \theta_{1}=\frac{1}{4} & \theta_{1}=\frac{1}{2} & \theta_{1}=\frac{3}{4}\end{array}$

$\begin{array}{lccc}\text { Existing Price }\left(\boldsymbol{p}_{\boldsymbol{A}}^{\boldsymbol{o}}\right) & & & \\ \text { Model Prediction } & 200 & 233 & 266.67 \\ \text { Experiment Mean } & 294.57 & 257.93 & 274.48 \\ & (10.43) & (8.02) & (9.20)\end{array}$

New Price $\left(\boldsymbol{p}_{A}^{n}\right)$

Model Prediction

$233.33 \quad 166.67 \quad 100$

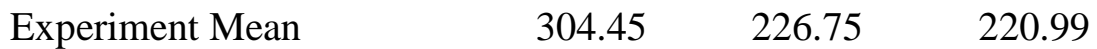

(12.09) (8.68) (9.68)

$\begin{array}{llll}\boldsymbol{p}_{\boldsymbol{A}}^{\boldsymbol{o}}-\boldsymbol{p}_{\boldsymbol{A}}^{\boldsymbol{n}} & -22.65 & 20.54 & -37.47\end{array}$

$\begin{array}{llll}\text { t- stat } & -1.52 * & 5.75 * * * & 6.55 * * *\end{array}$

Note: $*, * *, * * *$ denote significance at $1 \%, 5 \%$ and $10 \%$ respectively. Comparisons made based on last 10 rounds of data. Standard error in parenthesis (). 
Table 3: Prices and profits as a function of Treatment Variables

\begin{tabular}{cccc}
\hline & $\begin{array}{c}\text { Loyalty } \\
\text { Discounts }\end{array}$ & Aggressiveness & Profit \\
\hline \multirow{2}{*}{ Small Firm } & $\begin{array}{c}2.977 * * * \\
(0.389)\end{array}$ & -40.009 & -247.030 \\
& & $(36.493)$ & $(685.783)$ \\
Large Firm & $-1.543^{*}$ & $67.525^{*}$ & $-4,567.5225^{* * *}$ \\
& $(0.377)$ & $(38.356)$ & $(721.072)$ \\
Reciprocity & $-1.063^{*}$ & $21.231^{* *}$ & 678.190 \\
& $(0.564)$ & $(23.426)$ & $(440.228)$ \\
Constant & -0.500 & $151.153^{* * *}$ & $5,361.318^{* * *}$ \\
& $(1.653)$ & $(31.146)$ & $(1322.702)$ \\
LL & -318.929 & & 0.318 \\
$R^{2}$ & & 0.048 & \\
\hline
\end{tabular}

Note: $*, * *$ and $* * *$ denote significance at the $10 \%, 5 \%$ and $1 \%$ level, respectively. We regress log profit for scalability. Standard errors in parenthesis (). In the interest of space round dummies are excluded from the table. 


\section{List of Figures}

Figure 1: Comparison of Prices Across Treatments

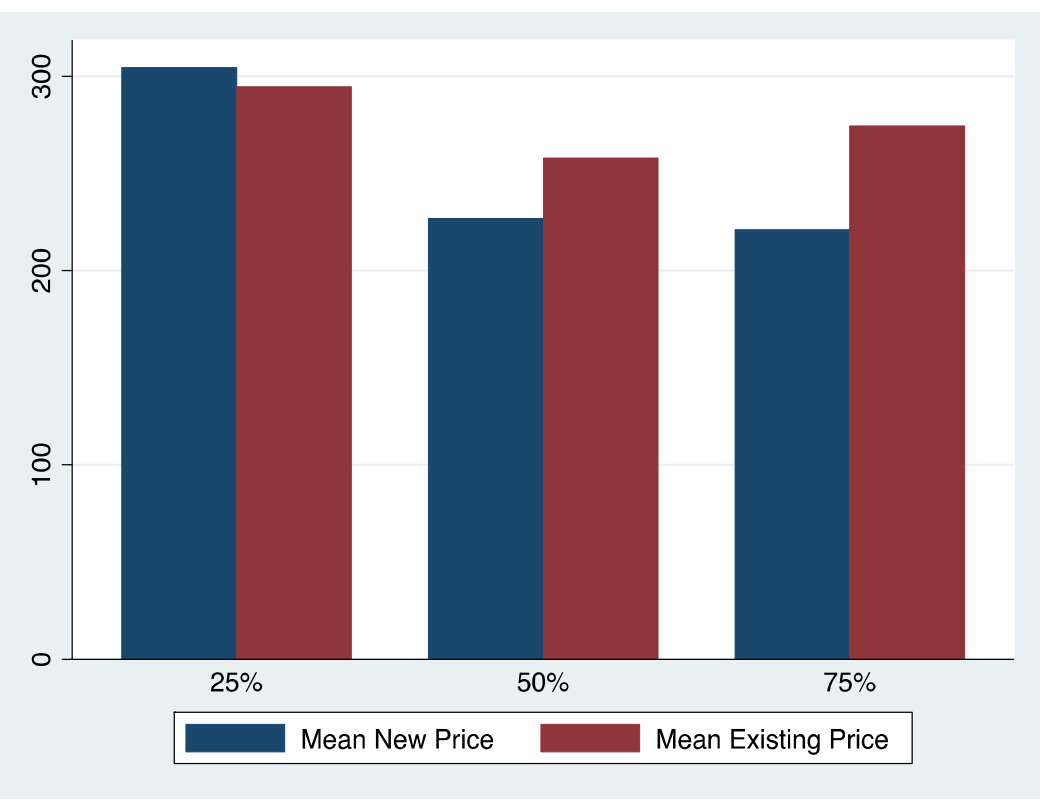

Figure 2: Aggressiveness in Pricing Across Treatments 


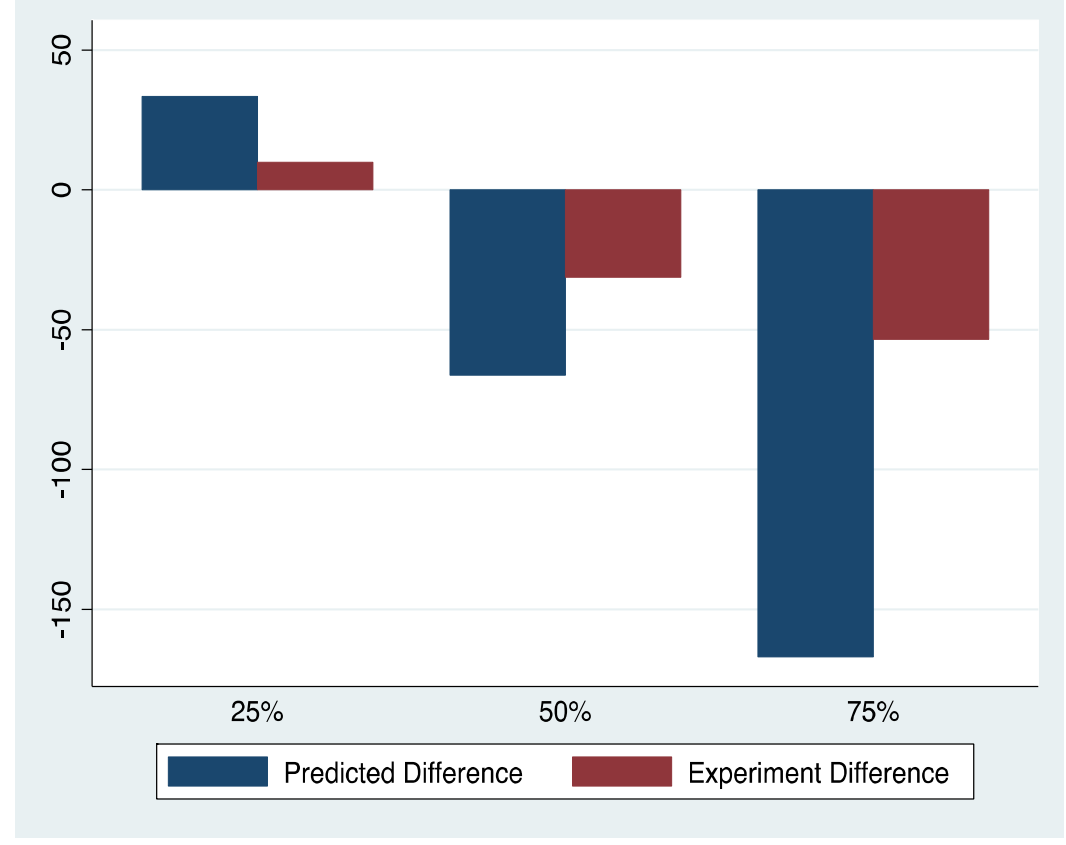

Figure 3: Offer Prices across Rounds

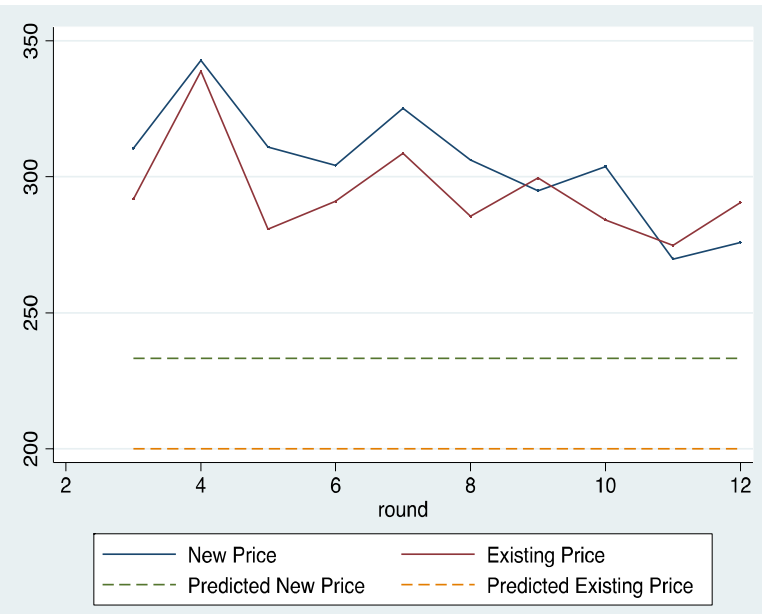

25\% Maket Share

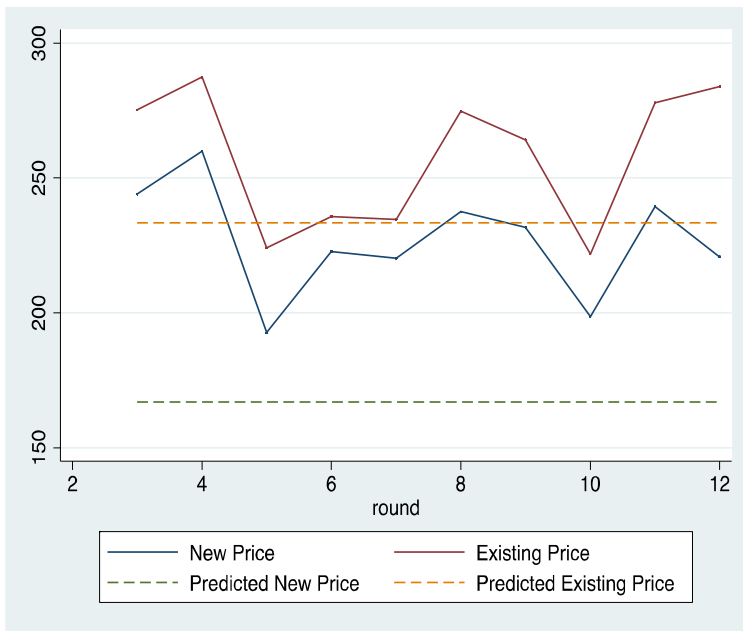

50\% Market Share 


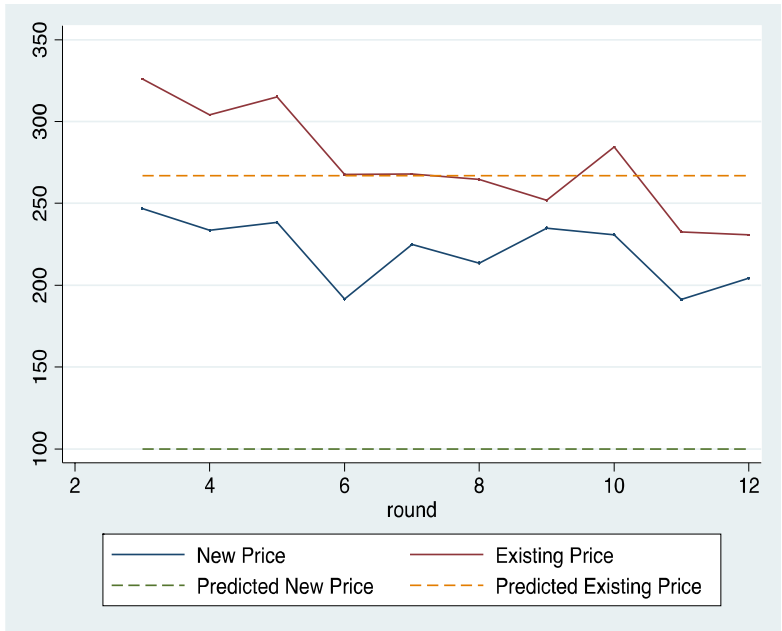

$75 \%$ Market share

Note: Solid line represents the average price across participants while dashed lines represents the theoretical prediction.

Figure 4: Comparison of Profit Across Treatments

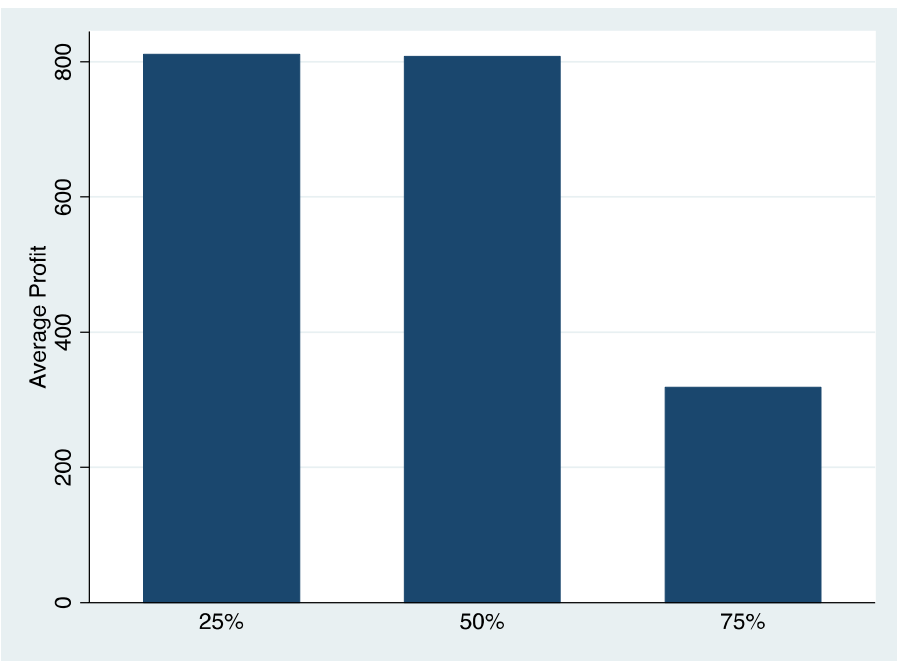




\section{Appendix A}

(i)Case I: $\theta \leq \frac{1}{4}$

$p_{A}^{o}=c+\frac{t(3-6 \theta)}{3} ; p_{A}^{n}=c+\frac{t}{3}(3-4 \theta)$

$p_{B}^{o}=c+\frac{t(3-2 \theta)}{3} ; p_{B}^{n}=0$

with $p_{A}^{o}<p_{A}^{n}$ and $p_{B}^{n}<p_{B}^{o}$

The firm with the small market share in Period 1 offers lower prices to existing customers

Now considering the implications on customer switching at these price levels. Recall that

$$
\begin{aligned}
\theta_{A} & =\frac{1}{2}+\frac{p_{B}^{n}-p_{A}^{o}}{2 t} \\
& =\frac{1}{2}+\frac{0-\frac{t(3-6 \theta)}{3}}{2 t} \\
\theta_{B} & =\frac{1}{2}+\frac{p_{B}^{o}-p_{A}^{n}}{2 t} \\
& =\frac{1}{2}+\frac{\frac{t(3-2 \theta)}{3}-\frac{t}{3}(3-4 \theta)}{2 t}=\frac{1}{3} \theta+\frac{1}{2}
\end{aligned}
$$

Firm A by offering loyalty rewards retains its existing customers and firm B is unable to attract new customers. Hence, in this case

$$
\begin{gathered}
\theta_{A}=\theta \\
\theta_{B}=\frac{1}{2}+\frac{1}{3} \theta
\end{gathered}
$$

Firm A and B's demand is

$$
D_{A}^{2}=D_{A}^{o}+D_{A}^{n}=\theta+\left(\theta_{B}-\theta_{1}\right)=\frac{1}{2}+\frac{1}{3} \theta
$$




$$
D_{B}^{2}=D_{B}^{0}+\underbrace{D_{B}^{n}}_{=0}=\left(1-\theta_{B}\right)=\frac{1}{2}+\frac{1}{3} \theta
$$

The resulting second period profits are:

$$
\begin{gathered}
\pi_{A}^{2}=p_{A}^{o} D_{A}^{o}+p_{A}^{n} D_{A}^{n}=\frac{t(3-6 \theta)}{3} \theta+\frac{t}{3}(3-4 \theta)\left(\frac{1}{2}+\frac{1}{3} \theta-\theta\right) \\
=\frac{t(3-6 \theta)}{3} \theta+\frac{1}{18} t(4 \theta-3)^{2} \\
\pi_{B}^{2}=p_{B}^{o} D_{B}^{o}=\frac{t(3-2 \theta)}{3}\left(\frac{1}{2}-\frac{1}{3} \theta\right)
\end{gathered}
$$

(ii) Case II: $\frac{1}{4} \leq \theta \leq \frac{3}{4}$

$p_{A}^{o}=\frac{t(2 \theta+1)}{3}$ and $p_{A}^{n}=\frac{t(3-4 \theta)}{3}$

$p_{B}^{o}=\frac{t(3-2 \theta)}{3}$ and $p_{B}^{n}=\frac{t(4 \theta-1)}{3}$

with $p_{A}^{o}>p_{A}^{n}$ and $p_{B}^{o}>p_{B}^{n}$

With reasonably symmetric baseline demand, both firms offer lower prices to potential new customers

At an interior solution it is always the case that

$$
\theta_{A}=\frac{1}{2}+\frac{p_{B}^{n}-p_{A}^{o}-\beta\left(p_{A}^{o}-p_{A}^{n}\right)}{2 t}
$$




$$
\theta_{B}=\frac{1}{2}+\frac{p_{B}^{o}-p_{A}^{n}-\beta\left(p_{B}^{o}-p_{B}^{n}\right)}{2 t}
$$

which yields

$$
\begin{gathered}
\theta_{A}=\frac{1}{2}-\frac{\theta-1}{(3)} \\
\theta_{B}=\frac{1}{2}+\frac{\theta}{3}
\end{gathered}
$$

This suggests that as consumers react more negatively to the price for new customers each firm has a further incentive to reduce the price to its previous customers. As a result the level of switching in is now

$$
\theta_{B}-\theta_{A}=\frac{1}{3}
$$

It is straightforward to obtain that at the interior solution, i.e., if $\frac{1}{4} \leq \theta \leq \frac{3}{4}$ firm A's second-period profit is given by

$$
\pi_{A}^{2}=p_{A}^{o} \theta_{A}+p_{A}^{n}\left(\theta_{B}-\theta\right)
$$

which equals:

$$
\pi_{A}^{2}=t \frac{10 \theta^{2}-10 \theta+5}{9}
$$

Similarly, it is straightforward to obtain that firm B's second-period profit:

$$
\pi_{B}^{2}=t \frac{5+10 \theta^{2}-10 \theta}{9}
$$

hence, both firms make the same profit. 
(iii)Case III: $\theta \geq \frac{3}{4}$ :

$$
\begin{gathered}
p_{A}^{o}=\frac{t(1+2 \theta)}{3} ; p_{A}^{n}=0 \\
p_{B}^{o}=\frac{t(6 \theta-3)}{3} ; p_{B}^{n}=\frac{1}{3} t(4 \theta-1) \\
\text { with } p_{A}^{o}>p_{A}^{n} \text { and } p_{B}^{o}<p_{B}^{n}
\end{gathered}
$$

The firm with the large market share in Period 1 offers lower prices to potential new customers

A's indifferent customer in Period 2 is located at:

$$
\begin{aligned}
\theta_{A} & =\frac{1}{2}+\frac{p_{B}^{n n}-p_{A}^{o}}{2 t} \\
& =\frac{1}{2}+\frac{\frac{1}{3} t(4 \theta-1)-\frac{t(1+2 \theta)}{3}}{2 t}=\frac{1}{3} \theta+\frac{1}{6}
\end{aligned}
$$

Similarly, firm B's indifference customer is located at

$$
\begin{aligned}
\theta_{B} & =\frac{1}{2}+\frac{p_{B}^{o}-p_{A}^{n}}{2 t} \\
& =\frac{1}{2}+\frac{\frac{t\left(6 \theta_{1}-3\right)}{3}}{2 t}=\theta
\end{aligned}
$$

Firm A and B's demand in the second-period is in this case:

$$
\begin{gathered}
D_{A}^{2}=D_{A}^{o}+\underbrace{D_{A}^{n}=\theta_{A}=\frac{1}{3} \theta+\frac{1}{6}}_{=0} \\
D_{B}^{2}=D_{B}^{o}+D_{B}^{n}=\left(1-\theta_{B}\right)+\left(\theta-\theta_{A}\right)=1-\theta+\left(\theta-\frac{1}{3} \theta_{1}-\frac{1}{6}\right)=\frac{5}{6}-\frac{1}{3} \theta
\end{gathered}
$$

and second-period profits are 


$$
\begin{gathered}
\pi_{A}^{2}=\left(p_{A}^{o}-c\right) D_{A}^{o}=\left[\frac{t(1+2 \theta)}{3 \beta+3}\left(\frac{1}{3} \theta+\frac{1}{6}\right)\right]_{\theta=\frac{3}{4}} \\
\pi_{B}^{2}=\left(p_{B}^{o}-c\right) D_{B}^{o}+\left(p_{B}^{n}-c\right) D_{B}^{n} \\
=\frac{t(2 \theta-1)(1-\theta)}{3}+\frac{1}{3} t(4 \theta-1)\left(\frac{2}{3} \theta-\frac{1}{6}\right)
\end{gathered}
$$

For $\theta=\frac{3}{4}$ :

$$
\begin{aligned}
\pi_{A}^{2} & =\frac{25}{72} t \\
\pi_{B}^{2} & =\frac{53}{144} t
\end{aligned}
$$




\section{Appendix B}

\section{Experiment}

Please respond to the following questions by selecting one option from the drop down

Q1. If someone does something that is beneficial to me, then I am prepared to return a favor, even when this was not agreed upon in advance

Q2. If I do something that is beneficial for someone else, then I expect that person to return a favor

Q3. In general, one can trust people

Q4. In these days you can't rely on anybody else

Q5. Most people try to take advantage of you if they got a chance

Q6. Most of the time people try to be helpful

Q7.When dealing with strangers it is better to be careful before you trust them

Hypothetical choice

Q8. When you have dinner in a restaurant, how much do you tip the waiter (as percentage of the bill) if a) the service is normal (Tipn)

b)the service is excellent (Tipe)

c)the service is poor (Tipp) 
Introductory screen

Thank you for participating in our experiment. In this experiment you will be participating in a series of price setting scenarios.

You are the pricing expert for Astra a company located in town $\mathrm{X}$. Astra deals in a wide range of products and services. The products and services are purchased repeatedly by customers living in town $X$. Astra's main competitor is Beta, which has a product selection identical to Astra and there are no differences in quality or service. In addition, both firms incur identical costs.

A computerised experimental participant will play the role of Beta and will play the profit maximising strategy.You will be setting the price for product $Y$ produced by Astra, a similar version is produced by Beta. You will make pricing decisions for Astra over multiple periods,

You must decide on the optimal pricing strategy that will maximize your earnings taking into acoount the competitor's strategy. Your payment will be dependent on the profit you make in the game, so make your decisions wisely.

Don't close your browser during session.

Next 


\section{Welcome to Round 1}

For simplicity you can assume that Astra and Beta are located at the two ends of town $\mathrm{X}$ and are $200 \mathrm{~km}$ apart, as below.

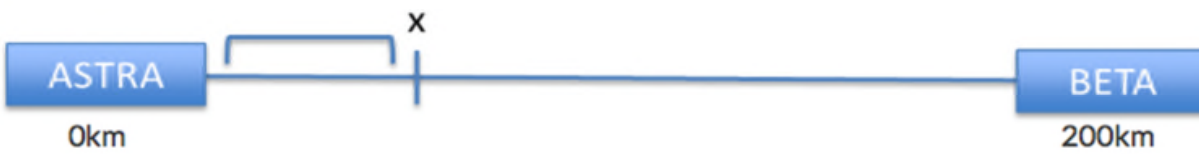

\section{Customers}

There are 200 customers located in the town and they are evenly distributed between Astra and Beta, such that there is 1 customer located per $\mathrm{km}$. Customers incur costs of traveling $X(0<X<200)$ (depending on their location). For customers right next to Astra $X$ is 0 and for customer right next to Beta $X$ is 200 . So that customers located close to Astra prefer Astra and customers located close to Beta prefer to go to Beta due to low travelling costs.

Customers are rational utility maximizers and purchase at the lowest price including transportation costs. If the price charged by Astra plus the traveling cost is too high customers would switch to Beta, likewise if Beta charges a very high price customers will switch to Astra.

A market research company also identifies two segments of customers:

- Existing Customers: Customers who purchased from Astra (you) in the past

- New Customers: Customers who purchased from Beta (your competitor) in the past

- Existing consumer's utility is defined as follows:

- 2000 - Price_Existing_Customers - $X$, where $X$ is the distance the customer located at $X$ has to travel to get to Astra

- New consumer's utility is defined as follows:

- 2000-Price_New_Customers - X, where X is the distance the customer located at X has to travel to get to Astra

PROFIT $=($ PRICE TO EXISTING CUSTOMERS - 100) $*$ NO. OF EXISTING

CUSTOMERS + (PRICE TO NEW CUSTOMERS - 100$)^{*}$ NO. OF NEW CUSTOMERS

25\% Astra 75\% Beta

\begin{tabular}{|l|l|}
\hline Astra's Existing Customers & $\begin{array}{l}\text { Astra's New Customers } \\
\text { (Beta's Existing Customers) }\end{array}$ \\
\hline 50 & 150 \\
\hline
\end{tabular}

Using this information you have the option to set two prices

1. Price to Existing Customers

2. Price to new Customers

Please set a price to Existing Customers( $\min 100, \max 2000$ )

Please set a price to New Customers( $\min 100, \max 2000$ )

Set price 


\section{Outcome}

Market Share

$38 \%$ Astra

$62 \%$ Beta

Feedback

\begin{tabular}{|c|c|c|c|c|c|c|c|c|}
\hline & $\begin{array}{l}\text { Astra's } \\
\text { Repeat } \\
\text { Customer }\end{array}$ & $\begin{array}{l}\text { Astra's } \\
\text { New } \\
\text { Customer }\end{array}$ & $\begin{array}{l}\text { Number } \\
\text { of } \\
\text { Customer }\end{array}$ & $\begin{array}{l}\text { Number } \\
\text { of } \\
\text { rExisting }\end{array}$ & $\begin{array}{l}\text { Number } \\
\text { of New } \\
\text { Customer }\end{array}$ & $\begin{array}{l}\text { Astra's } \\
\text { Profit } \\
\text { rs }\end{array}$ & $\begin{array}{l}\text { Beta's } \\
\text { Existing } \\
\text { Customer }\end{array}$ & $\begin{array}{l}\text { Beta's } \\
\text { New } \\
\text { r Customer }\end{array}$ \\
\hline & Price & Price & & Customers & & & Price & Price \\
\hline Market 1 & $\$ 678$ & $\$ 789$ & 50 & 30 & 45 & $\$ 48345$ & $\$ 778$ & $\$ 538$ \\
\hline
\end{tabular}

I am done with this round 